\title{
Vaginal Endometrioid Adenocarcinoma
}

National Cancer Institute

\section{Source}

National Cancer Institute. Vaginal Endometrioid Adenocarcinoma. NCI Thesaurus. Code C40251.

A rare adenocarcinoma that arises from the vagina with histologic features resembling the endometrioid adenocarcinoma of the endometrium. 